\title{
Salivary cortisol to assess the hypothalamic-pituitary-adrenal axis in healthy children under 3 years old
}

\author{
Margarete L. Silva, 1 Márcia C. Mallozi, ${ }^{2}$ Giesela F. Ferrari3
}

\begin{abstract}
Objective: To establish reference concentration intervals for salivary cortisol in healthy children, in the morning and in the afternoon, investigating factors that interfere with the concentration measured and the possibility that circadian rhythms are present.

Methods: A controlled observational study was carried out with 91 children aged 45 days to 36 months, selected at random and living in Santo André, state of São Paulo, Brazil. Inclusion criteria were: healthy, well-nourished, free from fever and corticoid use, subdivided by age group (five subsets) at 6-month intervals. Saliva was collected during home visits in the morning and afternoon. Cortisol was radioimmunoassayed with cortisol 3-oxime-bovine albumin antiserum.

Results: The five subsets exhibited higher cortisol concentration during the morning than in the afternoon $(p<0.001)$, and this difference passed $30 \%$ from 1 year of age onwards. Mean concentrations, in nmol/L, were 557.86 (morning) and 346.36 (afternoon). A negative linear correlation was observed between morning concentrations and hours' sleep and frequency of meals $(p<0.05)$, and in the afternoon with anthropometric measurements $(p<0.05)$.

Conclusions: Reference values for normal salivary cortisol in healthy children were established. At 45 days it was possible to observe circadian rhythms, which reached maturity at 12 months of life. Sleep and food deprivation increased morning cortisol levels.
\end{abstract}

J Pediatr (Rio J). 2007;83(2):121-126: Saliva, circadian rhythm, pituitary-adrenal axis, suppression.

\section{Introduction}

One major obstacle to interpreting laboratory tests of the hypothalamic-pituitary-adrenal axis (HPA) in pediatrics is the influence of fear and anxiety caused by invasive collection procedures, for example venous puncture, and by contact with strangers (physicians and the nursing team). This causes stress, altering the results of cortisol assays. ${ }^{1}$ Another peculiarity of children is the result of their immature metabo- lisms, which may cause unexpected complications during laboratory analysis, such as severe hypoglycemia during insulin tolerance testing. ${ }^{1}$

Pituitary-adrenal evaluation tests include the measurement of endogenous cortisol, known as basal cortisol, adrenocorticotrophic hormone (ACTH) assay and dynamic suppression and stimulation tests. Blood and urine samples are most often used in clinical practice for basal cortisol assay.

1. Mestre, Universidade Estadual Paulista (UNESP), Botucatu, SP, Brasil. Auxiliar de ensino, Disciplina de Pediatria, Faculdade de Medicina do ABC, Santo André, SP, Brasil.

2. Universidade Federal de São Paulo - Escola Paulista de Medicina (UNIFESP-EPM), São Paulo, SP, Brasil.

3. Doutora. Professora assistente, Disciplina de Pneumologia Pediátrica, Departamento de Pediatria, Faculdade de Medicina de Botucatu, UNESP, Botucatu, SP, Brasil.

This article is part of the dissertation entitled "Valores de referência de cortisol salivar para a avaliação adrenal em crianças menores de três anos, sem patologias" (Salivary cortisol reference values for the adrenal assessment of healthy children under 3 years old), presented at the Graduate Program in Pediatrics (Master's degree), Universidade Estadual Paulista (UNESP), Botucatu, SP, Brazil, on April 17, 2002.

Manuscript received Sep 11 2006, accepted for publication Nov 162006

Suggested citation: Silva ML, Mallozi MC, Ferrari GF. Salivary cortisol to assess the hypothalamic-pituitary-adrenal axis in healthy children under 3 years old. J Pediatr (Rio J). 2007;83(2):121-126.

doi $10.2223 / J P E D .1598$ 
However, these are both resources that suffer from certain negative aspects, the need for venous puncture and the difficulties involved in collecting urine with no losses in 24 hours, especially from infants and girls. ${ }^{2}$

Assaying cortisol in saliva is a method for evaluating adrenal function that offers ease of collection and is trustworthy. It is an alternative test and is more sensitive than plasma and urine-based techniques, in addition to offering repeated collections with no stress or blood letting. ${ }^{1,3-11}$ There is work in the literature that demonstrates the applicability of salivary cortisol assay to the study of circadian rhythms, ${ }^{12-15}$ to cognitive function disorders and to the influence of stress on the axis, triggered by anxiety, depression, panic syndrome and sleep deprivation. ${ }^{1}$ The most recent application for the method is for the diagnosis of Cushing's syndrome. ${ }^{2,16,17}$ Nevertheless, the literature provides scant information on the normal range of salivary cortisol in childhood.

The objective of the present study is to establish cortisol concentration measured from the saliva of healthy children under 3 years old, during the morning and afternoon, and to evaluate factors that affect the results of this assay. A further objective is to identify the presence of circadian rhythms and the age at which the HPA is mature.

\section{Methods}

This was a controlled, observational study that was approved by the Research Ethics Commission at the Faculdade de Medicina do $A B C$ and the Universidade Estadual Paulista (UNESP) - Botucatu, with free consent given by means of signature by parents or guardians. Ninety-one children aged 45 days to 36 months were enrolled and underwent salivary cortisol assay. Inclusion criteria were adequate nutritional status, with no history of heart disease, nephropathy or neuropathy, absence of fever for at least 48 hours and not having received systemic, inhaled or topical corticoids during the previous 15 days.

The children were selected by review of medical records from outpatients at the Faculdade de Medicina do ABC, in Santo André (SP), Brazil, in October 2001, checking for adequate nutritional status and appropriate age (inclusion criteria). For analysis, the sample was subdivided into 6-month age groups as follows: subset 1 : 45 days $1-6$ months; subset 2: $6 \mid-12$ months; subset 3: $12 \mid-18$ months; subset 4: $18 \mid-24$ months; subset 5: $24 \mid-36$ months.

Home visits were made during which anthropometric measurements were taken and a questionnaire applied that evaluated the number of meals and hours of sleep per day, in addition to the other inclusion criteria that had been set. Saliva samples were collected under supervision of the researcher during the morning (7 to $10 \mathrm{a} . \mathrm{m}$.) and afternoons (3 to 6 p.m.), respecting a minimum interval from meals of 30 minutes. ${ }^{18}$ For collection, $5 \%$ citric acid was instilled sublingually, provoking increased saliva flow. ${ }^{19}$ Between 0.5 and
$1 \mathrm{~mL}$ of saliva were aspirated from the oral cavity, transferred to an Eppendorf tube and stored in a freezer at $-20{ }^{\circ} \mathrm{C}$ until testing. ${ }^{9}$

The free fraction of salivary cortisol was determined in duplicate, in a single test, by radioimmunoassay without extraction, using antibodies to cortisol-3-oxime conjugated to bovine albumin. ${ }^{9}$ Using a mean corticoid pool at $251 \mathrm{ng} / \mathrm{dL}$, intertest variation was $11.5 \%$, and intratest variation was below $10 \%$, with a sensitivity of $1.7 \mathrm{nmol} / \mathrm{L}$. Salivary cortisol assay results are expressed in $\mathrm{nmol} / \mathrm{L}$ and percentiles.

Statistical analysis was performed using BioEstat 3.0. Student's t test was used to check that the sample was homogeneous in terms of the number of children in each subset, of morning/afternoon collection and in terms of the number of hours slept each night. Subsets were then compared with each other in terms of salivary cortisol assay results using Student's test and analysis of variance (ANOVA), with the level of alpha set at 0.01. Data were log-transformed because of their asymmetrical distribution. Factors that could impact on cortisol levels, such as sex, weight, stature, body surface area, number of hours' sleep at night and number of meals per day, were analyzed by multivariate linear regression.

Based on a $5 \%$ error and an a error of $1 \%$, a difference of $211.5 \mathrm{nmol} / \mathrm{L}$ between means and $136.4 \mathrm{nmol} / \mathrm{L}$ between standard deviations for the two groups (morning and afternoon) and with a variance $95 \%$, sample size was calculated at 71 children per group.

\section{Results}

The 91 children, 46 of whom were male, did not exhibit difference in terms of the distribution between the five age group subsets $(p=0.99$ ), time of saliva collection (morning, $p=0.17$; afternoon, $p=0.38$ ) or the number of hours slept $(p=0.37)$, demonstrating a homogeneous sample.

Comparison of morning and afternoon salivary cortisol assay results with Student's t test revealed that cortisol was higher in the morning for all ages ( $<$ 0.001) (Figure 1 ). According to ANOVA, the different age group subsets exhibited equal mean cortisol concentration ( $p>0.05)$, both in the morning and the afternoon (Figure 1).

Figure 2 illustrates median morning and afternoon salivary cortisol levels with their amplitudes, in percentages, for the five subsets. This amplitude is the difference between the median morning and afternoon cortisol measurements for each age group subset. Amplitudes greater than 30\% and with statistical significance (ANOVA) were observed from 12 months on (subset $3, p=0.0002$ ).

Mean ( \pm standard error) morning cortisol levels were $557.86 \pm 37.72 \mathrm{nmol} / \mathrm{L}$, with a range of 76.88 to $1,620.08 \mathrm{nmol} / \mathrm{L}$ (percentiles 2.5 to 97.5 ). The mean of afternoon levels was $346.36 \pm 23.42 \mathrm{nmol} / \mathrm{L}$, with a range of 50.92 to $1,169.36 \mathrm{nmol} / \mathrm{L}$ (percentiles 2.5 to 97.5 ) (Table 1 ). 
Salivary cortisol (nmol/L)

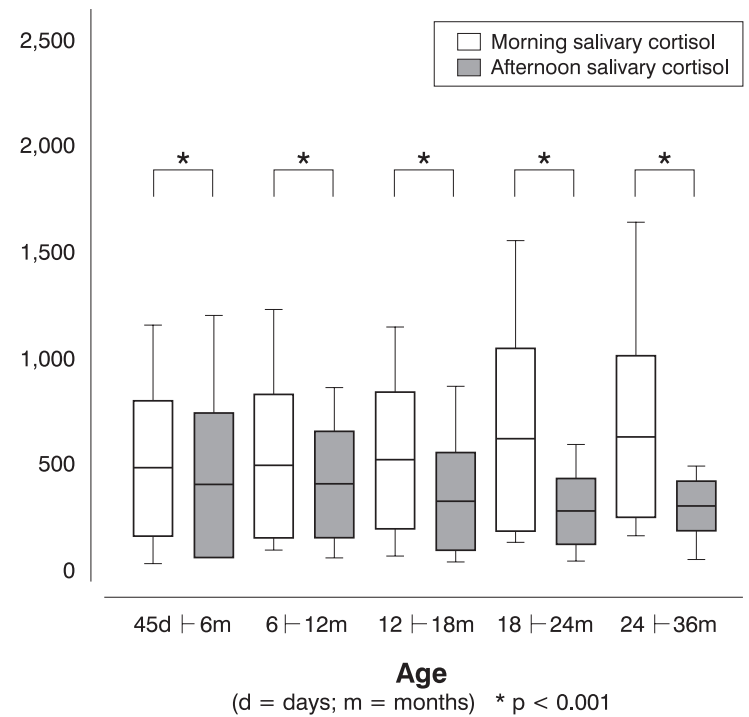

Figure 1 - Morning and afternoon salivary cortisol assay results by age $(n=91)$, represented in quartiles

The mean number of hours' sleep per night for the entire sample was $10 \pm 2.5 \mathrm{~h}(\mathrm{p}=0.37)$. Children less than 1 year old were eating eight meals a day, while children over 12 months ate four per day.

\section{Salivary cortisol (nmol/L)}

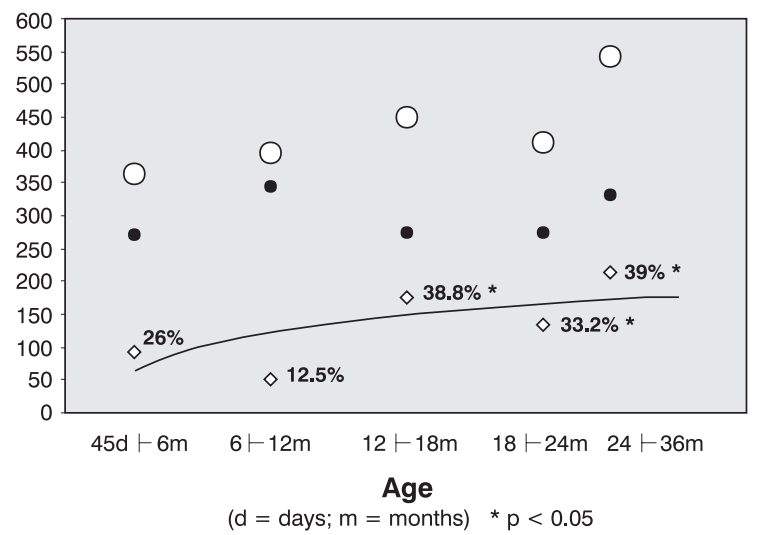

OMorning median $\bullet$ Afternoon median $\diamond$ Amplitude — Log. (amplitude)

Figure 2 - Percentage variation and amplitude trend for morning and afternoon salivary cortisol, by age $(n=91)$

There were negative linear correlations between morning cortisol and hours of sleep $(p=0.026)$ and number of meals per day $(p=0.017)$. No statistical differences were observed between sexes in morning ( $p=0.17$ ) or afternoon cortisol levels ( $p=0.46)$. Anthropometric measurements of weight, stature and body surface area demonstrated negative linear correlations with afternoon salivary cortisol $(p<0.05)$.

\section{Discussion}

The salivary cortisol assay appeared during the 1960s, with pioneering research that identified corticosteroids in parotid fluid. At the time, however, the impact was minimal because the techniques had low sensitivity and required impractical volumes of saliva. Radioimmunological methods for assaying steroidal hormones rekindled the interest in saliva measurements, and research carried out at the University of Wales Medical School in Cardiff demonstrated the practicality of the test in numerous publications. ${ }^{19}$

The radioimmunological method employs a supernatant, in this case centrifuged saliva, added to a cortisol-specific antibody and to radioactive cortisol. An equilibrium is established, similar to that in dialysis, between the concentration of radioactive cortisol conjugated to the antibody and the concentration of the salivary cortisol being assayed, also conjugated to the antibody. A liquid scintillation counting fluid is used to evaluate the concentration of the radioactive cortisol and antibody complex, thus indicating the concentration of free cortisol in the supernatant. ${ }^{9}$

What guarantees the quality of this method is the antiserum employed, depending on its affinity for steroid metabolites, the most widely used being cortisol-3-oxime conjugated to bovine albumin, originated from immunization of rabbits. This antiserum was synthesized at the Fleury laboratory by Prof. Dr. José Gilberto H. Vieira in $1975^{20}$ and is compatible with the best antisera described in the literature. The test has high specificity for cortisol (100\%), low crossreaction for cortisone $(8.5 \%)$, corticosterone $(1.6 \%)$, 11-deoxycortisol (7.9\%) and dexamethasone and budesonide (less than $0.1 \%$ ), and no significant cross-reactivity (less than $1 \%$ ) for other steroids.

In plasma, the majority of cortisol is bound to specific proteins, and it is the free fraction that is responsible for the hormone's biological activity. The salivary cortisol assay makes it possible to evaluate exclusively the free fraction of basal cortisol, with no need for methods of extraction that rely on the dialytic capacity of the basal membrane of the saliva glands. This is important because it increases the reliability of the technique, irrespective of whether there is hypoproteinemia. ${ }^{8-10}$ Another advantage is that saliva samples are stable at room temperature for 1 week, making it possible, for example, to send samples by post with no loss of cortisol activity. ${ }^{21}$ Furthermore, by collecting saliva at different times of day, circadian rhythms can be identified in a practical and noninvasive manner. ${ }^{1,6,8,11,14,15}$

Studies that have compared saliva assay with assays of free cortisol in plasma report a good correlation in children and adults. 2,4,9,13 The trustworthiness of saliva testing has been validated by concurrent testing of serum and saliva for variations in cortisol, even using different laboratory techniques, in response to stimulation tests with ACTH and suppression tests with dexamethasone. ${ }^{1,8,13,16,19}$ Jerjes et al. ${ }^{22}$ demonstrated that saliva assay is equivalent to 24 -hour urine collection for assessing the HPA axis in adults on corticoid therapy. 
Despite the applicability of salivary cortisol assays having been clearly demonstrated, it is surprising how little they are employed. It is only during recent years that the method has become better known, but there are still only a few studies with children. ${ }^{1}$ In our study, we observed that collection was quick and easy and could be performed in any environment with no need for major technical or structural resources, in addition to there being no risk of losing material, as can occur when attempting 24-hour urine collection with small children. The procedure does not cause patients to cry, since it causes no painful stimuli.

Cortisol is the principal endogenous glucocorticoid capable of interfering with organic activity, influencing retroinhibition of the HPA axis. Its synthesis is synchronic, with maximum levels in the morning, decreasing during the day and reaching a minimum at night, defining the circadian rhythm. Some of the factors that can interfere with the HPA axis, altering the circadian rhythm, are adrenal or pituitary tumors, ectopic ACTH production, surgery, sepsis, trauma, Addison's disease and, in particular, exogenous corticoid therapy.

In laboratory analyses of the HPA axis, it is important to take account of the possibility that the results of different techniques may be divergent, making interpretation of the true degree of organic compromise difficult. Cases have been recorded of patients treated with steroids who, even presenting growth deficits, fractures and cataracts, had normal laboratory results for morning cortisol plasma assays and synthetic ACTH stimulus tests. ${ }^{23}$ These findings placed real doubt on the quality of laboratory methods, leading to the need for them to be reconsidered.

Recognition of the superiority of salivary cortisol assay over plasma and 24-hour urine methods came in 2002 from the United States. ${ }^{24}$ Comparing it with corticoid therapy, the efficacy of salivary cortisol was demonstrated by Patel et al. ${ }^{25}$ monitoring patients on nasal corticoids, collecting saliva samples in the morning. These authors observed that salivary cortisol assay is a noninvasive and economic test with a positive predictive value of $100 \%$, compared with the ACTH test.

When evaluating the HPA axis, it is essential to respect the presence of the circadian rhythm. The decision of sample collection times was based on the results of previous studies. $1,12,14,26$ The drop in levels is clear in the results of our study, since, with the mean time of afternoon collection being 4 p.m., we observed differences between morning and afternoon assay results in all subsets.

Table 1 - Distribution by percentiles of morning and afternoon salivary cortisol assay results in children aged 36 months or less $(n=91)^{*}$

\begin{tabular}{|c|c|c|}
\hline & Morning salivary cortisol & Afternoon salivary cortisol \\
\hline Percentiles & $\mathrm{nmol} / \mathrm{L}$ & $\mathrm{nmol} / \mathrm{L}$ \\
\hline 2.5 & 76.88 & 50.92 \\
\hline 5 & 150.75 & 66.13 \\
\hline 10 & 204.16 & 118.61 \\
\hline 15 & 226.18 & 143.53 \\
\hline 20 & 254.39 & 174.74 \\
\hline 25 & 288.00 & 200.14 \\
\hline 30 & 309.83 & 212.89 \\
\hline 35 & 334.10 & 250.00 \\
\hline 40 & 398.26 & 268.44 \\
\hline 45 & 411.27 & 276.07 \\
\hline 50 & 462.43 & 291.91 \\
\hline 55 & 518.79 & 322.83 \\
\hline 60 & 549.13 & 347.98 \\
\hline 65 & 621.39 & 373.41 \\
\hline 70 & 670.52 & 426.01 \\
\hline 75 & 832.37 & 462.43 \\
\hline 80 & 944.51 & 504.62 \\
\hline 85 & $1,043.93$ & 568.79 \\
\hline 90 & $1,134.10$ & 693.64 \\
\hline 95 & $1,328.61$ & 899.42 \\
\hline 97.5 & $1,620.08$ & $1,169.36$ \\
\hline
\end{tabular}

Mean ( \pm standard error): morning cortisol, $557.86 \pm 37.72 \mathrm{nmol} / \mathrm{L} ;$ afternoon cortisol, $346.36 \pm 23.42 \mathrm{nmol} / \mathrm{L}$.

* Assay technique: competitive radioimmunoassay with cortisol-3-oxime antibody conjugated to bovine albumin 
Faced with the immaturity of children, there are doubts about the age at which circadian rhythms begin; the most up-to-date literature puts the start of this synchronization at 8 to 12 weeks. ${ }^{4,14,15}$ Other authors state that children may present differences in cortisol levels at different times of day, but that this difference will only attain an amplitude similar to that of adults when the rhythms have matured. Zurbrügg ${ }^{27}$ suggested that circadian maturity is possible from 2 years on.

The 91 children in our study exhibited higher morning than afternoon salivary cortisol levels $(p<0.001)$, defining the presence of rhythm in all subsets. Additionally, we noted that, as age increases, this difference between the morning and afternoon cortisol assay results becomes more evident, achieving statistical significance from 12 months on. According to Santiago et al. ${ }^{15}$ a circadian rhythm that has reached maturity should exhibit a mean difference of at least 33\% between cortisol assay results at different periods. In our analysis, this percentage difference was observed after 1 year, allowing for the conclusion that, in this population of healthy children, at 45 days of life it is possible to discern circadian rhythms, with full maturity above 1 year of age.

Countless environmental and behavioral factors, known as synchronizers, interfere with cortisol levels and, therefore, with circadian expression. A synchronizer does not create a rhythm, it merely influences its expression, altering the time of day at which it peaks, with sleep and food being the classic examples. ${ }^{28}$ The interference of diet with cortisol was illustrated by Oliveira et al., ${ }^{26}$ who assayed serum corticosterone in mice either feeding at will or with restricted diets, observing greater concentrations of corticosterone in the morning, when the diet was restricted, but failing to observe the same in the afternoons. With relation to sleep, serum cortisol is lower during rest than when active. ${ }^{29}$ Our results demonstrated a negative linear correlation between morning cortisol measurements and hours of nighttime sleep $(p=0.026)$ and also number of meals daily ( $p=0.017)$. This signifies that sleep and food deprivation function as stress mechanisms, increasing morning cortisol production, in accordance with reports in the literature. ${ }^{28}$

Since, without doubt, younger children eat more meals per day and sleep for longer, and since, according to the data described previously, this can be reflected in low morning cortisol levels, it is understandable that amplitudes of $33 \%$ or more occur after 1 year. Another interesting factor is that circadian rhythms appear at a similar chronological point in preterms as in full term infants, ${ }^{12}$ or even earlier. ${ }^{13}$ Based on these observations, we suggest that the factor involved in HPA axis maturity is not really a fixed date, but the influence of environment and of habits and culture.

We investigated factors that affect cortisol assay results and observed that sex did not exert any influence on results, in common with other authors. ${ }^{4,5}$ In contrast, weight, stature and body surface area all had a negative linear correlation with afternoon cortisol levels. No published reports were located in which only afternoon cortisol levels exhibited a negative correlation with anthropometric data in this age group. Kiess et al. ${ }^{5}$ reported that salivary cortisol assay results were dependent on age, particularly from 6 years of age on, with a positive correlation with puberty stage and with weight at all times of sample collection: morning, afternoon and night. These observations emphasize the influence of bodily development on cortisol levels, very probably linked with the hormonal changes that occur during adolescence.

Linder et al. ${ }^{30}$ assessed children and adolescents aged 8 to 17 years, demonstrating that daily cortisol production is almost 50\% lower in children (adolescents: $12 \mathrm{mg} / \mathrm{m}^{2} /$ day; children: $7 \mathrm{mg} / \mathrm{m}^{2} /$ day). This being so, we emphasize the importance of conducting studies to ascertain cortisol levels specifically for the pediatric age group and of the standardization of normal values for salivary cortisol assay results for early childhood, adolescence and adulthood. We were only able to locate reference salivary cortisol values for adults in the literature. Due to the homogeneity observed between age group subsets in our sample, it was possible to analyze all 91 samples with the intention of establishing normal reference values for the salivary cortisol levels expected of healthy children. The unit of salivary cortisol measurement was defined as $\mathrm{nmol} / \mathrm{L}$, since this is the most often used unit in the international literature, although we found Brazilian reference data in $\mu \mathrm{g} / \mathrm{dL}$ and in $\mathrm{ng} / \mathrm{dL}$. $^{1-3,9,12-16}$

\section{Conclusions}

Assaying basal cortisol in saliva is a simple method for screening for adrenal activity disorders and can be used with children in a practical and noninvasive manner. Interference factors that should be considered with this assay are sleep and food deprivation, which probably cause stress, increasing morning cortisol synthesis. Weight, stature and body surface area were negatively correlated with afternoon salivary cortisol levels.

For healthy children under 3 years old, tested using salivary cortisol radioimmunoassay with cortisol-3 oximebovine albumin antiserum, the mean expected value ( \pm standard error) for morning levels was $557.86 \pm 37.72 \mathrm{nmol} / \mathrm{L}$, with a range of 76.88 to $1,620.08 \mathrm{nmol} / \mathrm{L}$ (percentiles 2.5 to 97.5 ) and the afternoon value was $346.36 \pm 23.42 \mathrm{nmol} / \mathrm{L}$, with a range of 50.92 to $1,169.36 \mathrm{nmol} / \mathrm{L}$ (percentiles 2.5 to 97.5 ).

There is no doubt that at 45 days of life the circadian rhythm is present, however, it attains complete maturity, guaranteeing a similar response to adult behavior, from 1 year onwards, as observations of this sample have shown. What is important to emphasize is that, most probably, there are no fixed dates for expression of the circadian activity of the HPA axis. In fact, this period is moveable, being dependent on variations in the environmental characteristics and the habits of specific populations.

\section{References}

1. Castro M, Moreira AC. Análise crítica do cortisol salivar na avaliação do eixo hipotálamo-hipófise-adrenal. Arq Bras Endocrinol Metab. 2003;47:358-67. 
2. Castro M, Elias PC, Quidute AR, Halah FP, Moreira AC. Outpatient screening for Cushing's syndrome: the sensitivity of the combination of circadian rhythm and overnight dexamethasone suppression salivary cortisol tests. J Clin Endocrinol Metab. 1999;84:878-82.

3. Fogaça MC, Carvalho WB, Peres CA, Lora MI, Hayashi LF, Verreschi ITN. Cortisol salivar como indicador da função adrenocorticol em lactentes sadios com massagem terapêutica. Sao Paulo Med J. 2005;123:215-18.

4. Francis SJ, Walker RF, Riad-Fahmy D, Hughes D, Murphy JF, Gray OP. Assessment of adrenocortical activity in term newborn infants using salivary cortisol determinations. J Pediatr. 1987; 111:129-33.

5. Kiess W, Meidert A, Dressendörfer RA, Schriever K, Kessler U, König A, et al. Salivary cortisol levels throughout childhood and adolescence: relation with age, pubertal stage, and weight. Pediatr Res. 1995; 37:502-6.

6. Laudat MH, Cerdas S, Fournier C, Guiban D, Guilhaume B, Luton JP. Salivary cortisol measurement: a practical approach to assess pituitary-adrenal function. J Clin Endocrinol Metab. 1988;66:343-8.

7. Malamud D, Tabak L. Saliva as a diagnostic fluid. Ann NY Acad Sci. 1993;694:1-343.

8. Umeda T, Hiramatsu R, Iwaoka T, Shimada T, Miura F, Sato T. Use of saliva for monitoring unbound free cortisol levels in serum. Clin Chim Acta. 1981;110:245-53.

9. Vieira JGH, Noguti KO, Hidal JT, Russo EMK, Maciel RMB. Ensaio do cortisol na saliva como um método para avaliação da fração livre sérica. Arq Bras Endocrinol Metab. 1984;28:8-10.

10. Walker RF. Salivary corticosteroids: clinical and research applications. J Clin Chem Clin Biochem. 1989;27:234-5.

11. Woolston JL, Gianfredi S, Gertner JM, Paugus JA, Mason JW. Salivary cortisol: a nontraumatic sampling technique for assaying cortisol dynamics. J Am Acad Child Psychiatry. 1983;22:474-6.

12. Antonini SR, Jorge SM, Moreira AC. The emergence of salivary cortisol circadian rhythm and its relationship to sleep activity in preterm infants. Clin Endocrinol (Oxf). 2000;52:423-6.

13. Calixto C, Martinez FE, Jorge SM, Moreira AC, Martinelli CE Jr. Correlation between plasma and salivary cortisol levels in preterm infants. J Pediatr. 2002;140:116-8.

14. Custódio RJ. Avaliação da idade do aparecimento do ritmo circadiano do cortisol salivar em gêmeos [tese]. São Paulo (Departamento de Endocrinologia): Faculdade de Medicina de Ribeirão Preto; 2005.

15. Santiago LB, Jorge SM, Moreira AC. Longitudinal evaluation of the development of salivary cortisol circadian rhythm in infancy. Clin Endocrinol (Oxf). 1996;44:157-61.

16. Martinelli CE Jr., Sader SL, Oliveira EB, Daneluzzi JC, Moreira AC. Salivary cortisol for screening of Cushings syndrome in children. Clin Endocrinol (Oxf). 1999;51:67-71.

17. Papanicolaou DA, Mullen N, Kyrou I, Nieman LK. Night time salivary cortisol: a useful test for the diagnosis of Cushing's syndrome. J Clin Endocrinol Metab. 2002;87:4515-21.
18. Magnano CL, Diamond EJ, Gardner JM. Use of salivary measurements in young infants: a note of caution. Child Dev. 1989;60:1099-101.

19. Walker RF, Riad-Fahmy D, Read GF. Adrenal status assessed by direct radioimmunoassay of cortisol in whole saliva or parotid saliva. Clin Chem. 1978;24:1460-3.

20. Vieira JGH, Noguti KO, Rayol MP, Maciel RMB. Desenvolvimento e caracterização de método para a dosagem de cortisol livre urinário. Arq Bras Endocrinol Metab. 2000;44:233-8.

21. Chen YM, Cintron NM, Whitson PA. Long-term storage for salivary cortisol samples at temperature. Clin Chem. 1992;38:304.

22. Jerjes WK, Cleare AJ, Wood PJ, Taylor NF. Assessment of subtle changes in glucocorticoid negative feedback using prednisolone: comparison of salivary free cortisol and urinary cortisol metabolites as endpoints. Clin Chim Acta. $2006 ; 364: 279-86$

23. Food and Drug Administration, Center for Drug Evaluation and Research, Pulmonary Allergy Drugs Advisory Committee, Endocrinology and Metabolic Drugs Advisory Committee. Orally inhaled/intranasal corticosteroids and growth in children. Bethesda: FDA; 1998.

24. National Asthma Education and Prevention Program. Expert Panel Report: Guidelines for the diagnosis and management of asthma update on selected topics 2002. J Allergy Clin Immunol 2002;110:S141-219.

25. Patel RS, Wallace AM, Hinnie J, McGarry GW. Preliminary results of a pilot study investigating the potential of salivary cortisol measurements to detect occult adrenal suppression secondary to steroid nose drops. Clin Otolaryngol Allied Sci. $2001 ; 26: 231-4$

26. Oliveira MHA, Antunes Rodrigues J, Leal AMO, Elias LLK, Moreira AC. Circadian variations of plasma atrial natriuretic peptide and corticosterone in rats with continuous or restricted access to food. Life Sciences. 1993;53:1795-801.

27. Zurbrügg RP. Hypothalamic-pituitary-adrenocortical regulation. A contribution to its assessment, development and disorders in infancy and childhood with special reference to plasma cortisol circadian rhythm. Monogr Paediatr. 1976;7:1-83.

28. Spangler $G$. The emergence of adrenocortical circadian function in newborns and infants and its relationship to sleep, feeding and maternal adrenocortical activity. Early Hum Dev. 1991;25:197-208

29. Tennes K, Vernadakis A. Cortisol excretion levels and daytime sleep in one-year-old infants. J Clin Endocrinol Metab. 1977;44:175-9.

30. Linder BL, Esteban NV, Yergey AL, Winterer JC, Loriaux DL, Cassorla F. Cortisol production rate in childhood and adolescence. J Pediatr. 1990;117: 892-6.

Correspondence:

Margarete Lopes da Silva

Rua Sosuke Shigekiyo, 68 - Jardim Patente

CEP 04243-240 - São Paulo, SP - Brazil

Tel.: + 55 (11) 6947.1087

E-mail: igorlopes@uol.com.br 